So it would seem that a cause distinct from anything which we can identify as the special poison of puerperal fever may yet, by the influence which it exerts upon the woman in this peculiar condition, produce a disease not distinguishable by any of its phenomena from that assemblage of symptoms which we ordinarily call puerperal fever. It seems as if the puerperal state itself was the condition of the development of this set of symptoms. Moreover, we must remember that there is not any one single solitary cause to which we can refer the symptoms of puerperal fever. It occurs now from one cause and now from another. I remember at this moment the case of a lady in a state of perfect health, who was delivered at a time when puerperal fever was prevalent. She was a person in that position of society in which she was shielded from every possible danger. Soon after her delivery, she was exposed to a current of air, and caught cold. In a short time, the symptoms of puerperal fever developed themselves, of which she died. There was a case in which there was no special morbid poison existing-nothing but what could be derived from her own fluids, or brought about by some impression on the system. Moreover, we know that mental shock will have the effect of producing the symptoms of puerperal fever, leading to a fatal issue. I remember the case of a lady who progressed perfectly well after an easy labour; but, owing to some violent scene of domestic strife with her husband, she was seized almost immediately with symptoms of puerperal fever at a time when no such disease was prevalent, and of that disease she died.

I think, then, we are to look for the cause of puerperal fever rather to the condition present after delivery, than to any special poison. Poisons of various kinds may produce it. We know that, in Vienna, puerperal fever was exceedingly prevalent, owing, as was discovered, in a great measure to the fact that the students left the dissecting-room and went with their hands imperfectly clean to attend the women in their confinements; and when greater care was taken, when careful ablution and disinfectants were insisted upon, puerperal fever diminished in its frequency to a very great extent. We know that local violence may produce it: in short, we know that a great number of causes may give rise to it, and that the only one factor in the production of that class of symptoms consists in the special state of the woman after delivery. That state I need not recall. It is a state in which the fluids are laden with old, effete, and useless materials; laden also with materials out of which the old uterus is removed and a new one is to be built up. They are laden also with those elements out of which eventually the new secretion of milk is to be established. None of us except those few who, like Dr. Richardson, have given great attention to these inquiries, can describe at all wherein the alterations of the blood consists; yet, without indulging in any wild theory, we may say that there is a something. People used to call it a ferment. I do not care what it is called, providing we use the name not as defining the thing exactly, but as a name only to which we attach no other meaning than that of a something by which we are to distinguish this or that from the other, while as yet we know not its real nature. For instance, in the time of the old alchemists, calomel and corrosive sublimate, the chemical composition of which was unknown, were respectively called Draco magnus and Draco mitigatus; and, if we use names as the old alchemists used theirs, we shall be much more likely to keep from the error of hasty conclusions or rash generalisations, than if we use a name to which we tack a definite scientific meaning, while as yet we have no scientific grounds upon which to rest that meaning.

These were the chief things which it occurred to me might perhaps be worth the saying. Take a woman in the puerperal state checked in any manner, whether by poison from without, by mental shock, by cold, or by injury to the regular performance of those functions that ought then to go on, and you have the condition thereby produced out of which the assemblage of symptoms that we call puerperal feverand all the world is pretty well agreed to give it that name-arises. The only other word I would utter is to quote a saying of a great wise old physician, who said that the highest aim of our art must be the greatest possible generalisation of diseases and the greatest possible individualisation of our patients; so that we have in each case to look, in the prevention of puerperal fever, not simply to the removing of possibility of contagion, not simply most carefully watching the local condition of the uterus and removing from its inner surface any possible decaying matter, not simply to the taking care that the air that surrounds the patient is good, but we are bound also to consider the patient's mental state, to regard minutely her individuality, and, if we wish to put a stop to the disease, to remove from around or from within our patient anything which can interrupt those important processes, the interruption of which gives rise to these symptoms, which we designate by the name of puerperal fever.

\section{CONCEALMENT OF VENEREAL DISEASE IN THE ARMY.}

\author{
By JOHN AMBROSE, B.A., M.D., Surgeon A.M.D., \\ "Attached", 58th Regiment.
}

THE discussion which followed the reading of Mr. Acton's paper before the Royal Medical and Chirurgical Society, the recent Parliamentary debate, and numerous other signs and tokens, indicate the avidity with which the opponents of the Contagious Diseases Acts would add to their other objections to these statutes that of failure to compass all the good, in the way of disease-prevention, which might reasonably be expected of them. It, therefore, behoves those who are interested in the efficient working of these Acts to leave no means unsuggested of ensuring for them as large an amount of success as it is possible to achieve. At present, our efforts to control the propagation of venereal disease consist chiefly-I might almost say solely -in the care taken to bring under examination and, when necessary, hospital treatment, the prostitutes with whom our soldiers consort in certain military stations. This, obviously, is the step best calculated to strike directly at the root of the evil to be overcome, and the one without which any other measures would be likely to be of little avail. But, at the same time, what I may call subsidiary measures should be taken into account, and I should like to draw attention to one or two such, which I venture to think may be profitably considered.

During the past year and a half, a soldier admitted to hospital with primary syphilis or gonorrhœa (relapses excepted) loses the whole of his pay for the time he is under treatment for either of these diseases. Before considering the influence which this deprivation of pay appears to me to exert upon the amount of venereal disease in the army, I shall mention the other point of which I desire to speak, because the two subjects may be, I think, conveniently discussed conjointly. The other point is this : it was formerly the duty of the regimental medical officers to subject the men of the corps to which they belonged to a periodical inspection for the detection of venereal disease ; but for some years this duty has been relinquished. If now we glance at our proceedings with reference to our mode of dealing with these contagious complaints for the last ten years or so, we find that, while, with the one hand, we have imposed certain salutary, if irksome and disagreeable, periodical inspections upon prostitutes, we have with the other hand exempted our soldiers from these very inspections to which, be it remembered, these same prostitutes have been subjected purely and solely for the benefit of the army and navy. Further, in the same decade, a measure has been introduced by which a soldier who confesses himself to be the subject of gonorrhœa or syphilis forfeits the whole of his pay while in hospital. There is now no substantial reason why a soldier suffering from a comparatively trivial, though none the less contagious, form of disease should not conceal and impart it to one or more of the women who, on his account, are submitted to a periodical examination. In this way, some of the good effected at the Lock Hospitals is, I fear, undone ; and the drawback is not likely to be favourably affected by the fact, that the soldier frequently prefers avoiding the restraint of a residence in hospital, and devoting some of the pay of which he would be deprived in the event of his being admitted there, to remunerating a neighbouring chemist and druggist for the treatment he requires. The soldier, by so acting, no doubt transgresses the regulations, but he retains his liberty and his money. I say nothing here of the after-effects that irregular, and often insufficient, treatment of this kind must exert upon the man's constitution. The following brief narrative of facts will illustrate the remarks I have made, and prove that $I$ have not been conjuring up imaginary difficulties.

The 58 th Regiment came home from India in March of last year, and occupied the Anglesea Barracks at Portsmouth-a "protected" station-until April of this year. The amount of venereal disease in the regiment during 1874 was comparatively small, which gratifying circumstance I, in common with others, accepted as an indication of the satisfactory working of the Contagious Diseases Acts at Portsmouth. This explanation was, I believe, to a large extent, correct, and I do not consider that what I am now about to say in any way invalidates the comparison drawn by Dr. Parkes, in the BRITISH MEDICAL JOURNAL of February 2oth, between the 58th and Io6th Regiments, at Portsmouth and Parkhurst respectively, since the same condition of things which I am now about to describe must have existed in the ro6th as in the 58 th. When, however, month by month the admissions to hospital, in the 58 th, on account of venereal disease, became still fewer and fewer, until, in January and February of this year, they numbered only three; and when, in the last week of February, there was not a case of either gonorrhœea or syphilis under treatment, I could not 
help suspecting that some additional cause was in operation. On March Ist, I therefore addressed the principal medical officer officially on the subject, informing him that I suspected disease was being concealed, and requesting that I might be allowed to put my suspicions to the test by means of a "health-inspection". This permission was, with the approval of the lieutenant-general commanding the Southern District, readily vouchsafed, and I accordingly examined 447 lancecorporals and privates. I found that, of this number, 28 , or 6.26 per cent., were the subjects of venereal disease, which, two or three of the cases perhaps excepted, was obviously of some considerable standing. The twenty-eight cases comprised eleven of primary syphilis, four of gonorrhoea, eleven of gleet, and two of balanitis. Those of the chancres were cicatrising ; and the large amount of gleet discovered bears ample testimony to the fact that gonorrhœa, although concealed, had previously been present on a very considerable scale. It may be as well to mention that the senior medical officer at the Garrison Hospital, to which these twenty-eight men were forwarded for treatment, coincided in my diagnosis of each case. I have served for nearly cleven years with the 5 sth Regiment, and an consequently, I believe, tolerably well acquainted with the characters, mole of feeling, etc., of many of these twenty-eight men. I, therefore, claim to be in a position to judge, with about as much accuracy as a question of this nature is susceptible of, how far this concealment was attributable to one cause or set of causes, and how far to another. I need not tell any one conversant with the ways and customs of soldliers that it would, as a very general rule, be utterly in vain to expect that they would give a straightforward and satisfactory answer to the question, Why have you concealed your disease? When cletected, the soldier is apt to be sulky, uncommunicative, and fully impressel with the idea that the fewer admissions he makes the better for himself. He has (no matter how one may endeavour to convince him to the contrary) a hazy indefinite suspicion that anything he might say would be afterwards used to his disadvantage. Abrupt direct questioning would, therefore, be likely to defeat its object, and I did not attempt it. The men were under my care in the Garrison Hospital, so I had ample opportunities afforded me of ascertaining their sentiments, indirectly and leisurely. This I did, and the result is, that $I \mathrm{am}$ perfectly persuaded the great majority were led to conceal their disease altogether for the purpose of avoiding retrenchment of their pay in hospital, while a minority-seven out of the twenty-eight-were actuated, in addition, by other motives, such as dislike of hospital restraint, and, in the case of officers' servants, special orderlies, etc., unwillingness to risk the loss of remunerative and congenial employment. I have also made inquiries of several intelligent and reliable non-commissioned officers, whose opinions unanimously and abundantly corroborate this. I need hardly say that, mixing with the men, and overhearing barrack-room conversation, as they do, these non-commissioned officers are not likely to be mistaken; and being themselves, in most instances, married, they could have no conceivable motive in misrepresenting matters. I accordingly look upon their evidence as absolutely conclusive, even apart from the fact that their opinion commends itself so thoroughly to common sense. The conclusion is forced upon me, that this extraordinary amount of concealment was chiefly due to a dislike on the part of the men to put themselves in the way of having their pay retrenched; and, in a ninor degree, to other causes, the result of which could only have bcen obviated by subjecting the seven men concerned to an efficient system of "health. inspection".

If the interests of the Contagious Diseases Acts were alone to be taken into account, my experience would seem to furnish grounds for, at any rate, suggesting the propriety of remitting the retrenchment of pay to which a soldlier is now liable, and of again having recourse to a system of health-inspections in the army. But, being fully a ware that such interests are not the only ones to be regarled, and as it would appear scarcely probable that retrenchment of the soldier's pay was adopted, or periodical health-inspections relinquished, without deliberation having been bestowed upon all the attendant circumstances apparent at the time of deliberation, it would be unbecoming on my part to recommend a change. I do not for a moment presume to question the desirability of either of these measures, viewed as a whole, but restrict myself to the office of indicating how the Contagious Diseases Acts-which, it should not be forgotten, are cven yet on their trial---seem to me to be affected by the presence of retrenchment and the absence of inspection, leaving it to others, who are in a position to take a more comprehensive and able view of the question than I am, to say what should or should not le done.

With regard to the possible reintroduction of heath-inspections, I should like to make a few anticipatory remarks. Formerly, and when these inspections were in vogue, each regiment serving at home was provided with two medical officers. Now, a regiment has only one medical officer attached to it. This one officer, when required to attend the sick of his regiment, as is frequently the case, has his time fully occupied. To inspect five hundred men thoroughly - and, if not performed thoroughly, the examination would be worse than useless, as it would be misleading-would occupy about seven hours of one examiner's time. This would be a very serious addition to the labours of an already sufficiently worked man; nor would the addition be one such as would tend, by agreeable diversification of his task, to invigorate the labourer. On the contrary, a more disagreeable duty could not easily be imposed upon a medical officer. For these and other reasons to which I deem it advisable not to allude here, I would venture to suggest that, in the event of health-inspections being revived in the army, medical officers should be specially appointed to conduct them. A few inspectors, selected on account of energy, intelligence, and aptitude, might be so distributed over the United Kingdom as to bring all the soldiery stationed therein within a really effective system of supervision. Resident in London, Dublin, Edinburgh, and perhaps one or two other military centres, these inspectors might be allowed access to the returns and other sources of information relative to their duties which are, from time to time, received at the offices of the Army Medical Department in these cities. They would, I doubt.not, soon learn to interpret these returns, so as to be able to form a pretty accuratc opinion as to the corps in which their inspectorial services would be most required, particular attention, of course, being paid to the regiments occupying or about to occupy "protected" stations. Should suspicion be aroused that disease was being concealed in a particular regiment, it should be pounced upon by an inspector; no more warning being given to the regiment than the few hours necessary to get the men together, and to prepare nominal rolls of each company for the inspector's guidance. If soldiers once know that they are liable to be thus examined at uncertain times, and without notice, and if every man detected in the act of concealment be punished to the extent prescribed for this offence in the Queen's Regulations, we should not, I believe, be much more troubled by disease-concealment in the army.

\section{ON THE ACTION OF MEDICINES : OLD AND NEW.*}

By JOHN KENT SPENDER, M.D.Lond., Surgeon to the Mineral Water Hospital, Bath.

II.

A'T the conclusion of my last paper, I spoke of the treatment of chronic pulmonary consumption by the application of blisters. I believe it was long ago affirmed that phthisis rarely occurred in any one even but slightly marked with small-pox. Dr. Copland observed that a copious eruption of acute small-pox often cured pulmonary consumption in an early stage, but as often accelerated the progress of the disease in an advanced stage. Other writers have stated that phthisis is hardly ever seen in persons much marked with small-pox, but I cannot confirm this assertion from my own experience. Certainly, however, it has been known from the earliest period of medical history that the development of a purulent eruption has sometimes cured consumption in the chest; and, in the early part of this century, the doctrine was: firmly established that pustular eruptions and purulent discharges artificially produced have more or less influence in delaying or arresting the progress of consumption when the disease is not too far advanced. Even the "potential cautery" was not unfrequently used in old times for the same purpose.

The medical antiquarian is apt to consider a practical subject from a different stand-point from the busy practitioner. 'The latter is necessarily very much governed by current theorits, and their acceptance by the literary leaders of the profession; and it is a fact that there has been a considerable change of opinion cluring the last twenty years on what is called "counterirritation". This change of doctrine is clue partly to new physiological views of the influence of nerve-centres on the nutrition of distant organs, and partly to a growing distrust of the efficacy of outward applications. Sharing heartily in this distrust as regards a vast crowd of empirical things, I must yet announce myself a firm believer in the utility of the old-fashioned blister, the emflastrum cantharidis. liut what a ridiculous caprice it is that fashion has anything to do with our choice of remedies! I have discussed, in my Fothergillian Essay, the scope of blisters in the relief of pain, and it is certain that they are not less useftil in the treatment of some constitutional disorders.

It is within the experience of nost medical men that enlargement or

* Vide Britisu Mevical Jouknal, September 27th, 1873 . 